\title{
Research and Practice on the Reform of Practical Teaching System in Translation for English Majors
}

Wang Juan

School of Foreign Language, Yangtze University, Jingzhou, Hubei, P. R. China

Type of Work: Peer-Reviewed

DOl: http://dx.doi.org/10.21013/jems.v15.n4.p5

How to cite this paper:

Juan, Wang. (2019). Research and Practice on the Reform of Practical Teaching System in Translation for English Majors. IRA International Journal of Education and Multidisciplinary Studies (ISSN 2455-2526), 15(4), 141-147.doi: http://dx.doi.org/10.21013/jems.v15.n4.p5

(C) Institute of Research Advances.

This work is licensed under a Creative Commons Attribution-Non Commercial 4.0 International License subject to a proper citation to the publication source of the work.

Disclaimer: The scholarly papers as reviewed and published by the Institute of Research Advances (IRA) are the views and opinions of their respective authors and are not the views or opinions of the IRA. The IRA disclaims of any harm or loss caused due to the published content to any party.

Institute of Research Advances is an institutional publisher member of Publishers International Linking Association Inc. (PILA-CrossRef), USA. The institute is an institutional signatory to the Budapest Open Access Initiative. Hungary advocating the open-access of scientific and scholarly knowledge. The Institute is a registered content provider under Open Access Initiative Protocol for Metadata Harvesting (OAI-PMH).

The journal is indexed \& included in WorldCat Discovery Service (USA), CrossRef Metadata Search (USA), WorldCat (USA), OCLC (USA), Open J-Gate (India), EZB (Germany) Scilit (Switzerland), Airiti (China), Bielefeld Academic Search Engine (BASE) of Bielefeld University, Germany, PKP Index of Simon Fraser University, Canada.

This work was supported by the Yangtze University Teaching Research Project under Grant JY2017023. 


\begin{abstract}
The educational circles propose that we should attach importance to experimental teaching. As mentioned, we should fundamentally change the orthodox concept of experimental teaching depending on theoretical teaching, fully understand and implement the status of experimental teaching in school talent cultivating and form the idea and atmosphere overall coordination between theoretical teaching. The author attempts to optimize the course of English major translation so that the teaching content can be integrated into the whole practical teaching. Meanwhile, the practical teaching system should be reformed to break through the conventional teaching framework of practical teaching. What' more, we should vigorously carry out the second class activities and combine the practical teaching in translation and innovative practice implemented by the school with the tutor' studio. Also, in this process, we should pay attention to the cultivation of students' innovation ability so as to combine the practical teaching system with the translation theory course, which can enhance students' ability to combine the theory with practice.
\end{abstract}

Keywords: English translation, major practical teaching, innovation and entrepreneurship

\title{
I. Introduction
}

Since the 19th century, the University of Berlin in Germany, the Massachusetts Institute of technology in the United States as well as Peking University and Tsinghua University in China have begun to alter their educational concepts with a series of major reforms. At present, our educational circle advances that we should attach importance to experimental teaching. As mentioned, we should fundamentally change the orthodox concept of experimental teaching depending on theoretical teaching, fully understand and implement the status of experimental teaching in school talent cultivating and form the idea and atmosphere overall coordination between theoretical teaching. With such guiding ideology, all colleges and Universities, such as Huazhong University of Science and Technology, Zhejiang University and Central South University, have formed a relatively mature practical teaching system.

In our school, practical teaching has been listed as one of the teaching works. In 2013, after promoting the reform of talent cultivating, we carefully held a good practice teaching meeting and develop the reform pilot work of teaching method and student learning effect evaluation system. In 2016, a new undergraduate and a new teaching syllabus were revised, in which practice credits were greatly increased. For example, in the school of foreign languages, professional practice compulsory content accounted for $9.7 \%$, elective content accounted for $14.2 \%$, innovation and entrepreneurship compulsory content accounted for $1.3 \%$, and elective content accounted for $2.6 \%$.

According to the talent cultivation program for English majors in 2016, the practical teaching of English majors is reflected not only in classroom teaching but also in students' extracurricular learning and practical activities. "Classroom teaching should be combined with students' extracurricular learning and practical activities. Extracurricular learning and practice are the extension and expansion of classroom teaching. And they are also an important way to cultivate and develop students' abilities" [1]. The main practical links of English majors are related to professional practice courses and innovative entrepreneurship activities. In view of the content of the talent cultivation program for English majors 
in 2016, the translation direction of English majors in the school of foreign languages has also developed corresponding practical teaching content. How to actively expand the cooperation between the school and domestic colleges and universities, and between the school and the enterprise, so as to help students majoring in English translation to improve their language usability and practical translation ability?

When carrying out the training program in edition of 2016, we found that many problems, for example, the teaching system is incompatible with the essential content, the development of practical teaching teachers is not balanced,the management system is not perfect,the effect of internships is not ideal and the practical teaching equipment is backward,emerge in a rush. Therefore, the author attempts to solve the following problems through investigation and research: first, what are the problems in the practical teaching system of translation in our school? Second, how can we deal with the relationship between theoretical knowledge and practical teaching in English Translation Major? Third, what is the innovation of the practical teaching system of translation for English majors based on the 2016 undergraduate talent cultivation program?

\section{Current situation and problems of practical teaching system of translation for English majors}

According to the undergraduate talent training program of the school of foreign languages in 2016, "the school of foreign languages has established a complete set of undergraduate practice system, namely, a composite application talent training mode oriented by social needs. It includes the extracurricular language application ability practice platform with the foreign language culture festival as the core; Cognitive practice platform combining theory with practice; A centralized and unified platform for graduation practice; College students' innovation and entrepreneurship training platform "[2]. According to this training program, the author firstly studies and analyzes the current practical aspects of translation in English major, as shown in the following figure:

In the main practice links, we found that innovation and entrepreneurship accounted for $23.9 \%$ of the maximum credit, while personality development and professional practice respectively accounted for $3.9 \%$ of the credit. Among the required courses of professional translation theory courses, only translation theory and practice, which is offered in the fifth semester. Elective courses in translation course, in theory, are available in the third and fourth semester including "translation 1-2", "interpreting 1-2" , and the comparison between English and Chinese in the fourth term, the simulated real interpretation, the simulation of simultaneous interpretation in the fifth semester opening, the style and the translation of the sixth semester opening, the seventh semester opened the discourse translation and translation studies. Elective courses about translation direction within professional practice courses are only available in the sixth semester, which comes from the course of application translation, while theory and use on innovation, entrepreneurship, and personality cultivation education were only put into effect in the university's paper plan about them.

Firstly, in the training program, the importance of professional practice is indeed highlighted in the credit ratio. The fact is that the content and system of practical teaching have been updated, but the theoretical knowledge of translation courses is divorced from practice. For example, in the third and fourth semesters, "translation 1-2" and "interpretation 1-2" are offered, but the corresponding professional practice teaching is an empty talk or just a shell. From the beginning of the third semester 
to the sixth semester, the practical teaching content in the translation direction must compliment the professional theory courses, so as to achieve the effect of combining theory with practice. From the second half of 2013 till 2016, there are no ever related practical courses for English majors in translation.

Secondly, the practice of innovation and entrepreneurship is independent and disconnected from the tutor's studio. There is a "practical training workshop for English translation" in the tutor's studio of the translation direction of the school of foreign languages, but the person in charge is not any of the full-time teachers of the translation direction or even none of the members, but teachers from other directions. From 2013 to 2016, the proportion of English major translation in college, university and national innovative projects is shown in the following table. From the table, we can find that the number of innovative projects in English translation from 2013 to 2016 accounted for $0.65 \%, 1 \%$ and $0 \%$ at the school level. District level accounted for 4.7\%,0\%, $0 \%$; The national level accounts for 3.1\%, 2\% and $2.2 \%$. Therefore, the tutor studio, innovation and entrepreneurship, and the related professional theory courses and professional practice courses are independent and disjointed.

Thirdly, the construction and development of the teaching staff of practical teaching are unbalanced and the management system is incomplete. The school of foreign languages has 78 teaching and administrative staff, including 73 full-time teachers, 7 professors, and 18 adjunct professors. There are 37 teachers who have obtained a master's degree or above, including 5 doctors and 7 doctoral candidates. In the English major, there are 10 teachers who are concerned with the translation courses, but only one of whom is connected with practical works about innovation and entrepreneurship in nearly 3 years. The teaching staff of practical teaching does not form a system and stays in disorder. Most teachers become a member of it just for the promotion of title in the future. As a result, the teaching staff of practical teaching forms an unbalanced development. And the school of foreign languages does not have formed an evaluation system--management system.

Fourthly, the lab and practical teaching device were equipped but they do not get an update and fitted in time. Although the school of foreign languages owns practical teaching labs in translation-oriented English major, they are used as multimedia classrooms. The using situation of resources and devices is unsatisfactory and they cannot play a role fully.

Fifthly, the graduation internship platform has been established but the practice effect was out of satisfaction. Students just want to earn practice credits neglecting the real practice purpose and cannot connect theory with practice. The completion status of the graduation thesis is unsatisfactory. Some students do not choose a translation-oriented thesis because it is high in difficulty and wasteful in time. Most students choose an education-oriented, culture-oriented or literature-oriented thesis. Accordingly, the completion status of the graduation thesis is not satisfactory enough.

\section{The reform of practical teaching in English major translation}

In the undergraduate personnel training program (2016), practical teaching consistently is one key point of teaching works and an important part of professional personnel training. The practical teaching system of the undergraduate personnel training program (2016) consists of class practice, professional practice and innovative practice, including regular course practice, graduation practice, graduation 
thesis and the cultivation of innovation capacity. This personnel training program has formed the mainframe that practical course is the base, the design of graduation thesis is main orientation, the graduation practice is the main structure and the innovation capacity cultivation is an extension. Consequently, personnel training in English major translation should put practical capacity cultivation in the first place. In order to promote teaching work and enhance teaching quality, we should carry out reform and innovation in the following aspects:

First, from the perspective of English professional translation, by basing the existing 2016 English major undergraduate talent training program, as well as combining the requirements of the society for English professional translation talents, we optimize the curriculum system and practice of English professional translation direction, organically unify all the practical teaching links, run through the four-year undergraduate education, and at the same time integrate the teaching content into the whole practice teaching body. The relevant translation professional courses involved in our 2016 talent training program starts from the fourth semester, but the real-time for students in the school is only 7 semesters. This kind of curriculum system sets the students to feel relaxed in the first and second semesters, however, as for the fourth, fifth, and sixth semesters, students are is busy rushing for courses and credits. As a result, for the lower grade students, we teachers should pay attention to the cultivation of the basic skills of students. By relying on the cultural festival of the Foreign Languages Institute, we can strengthen the students' ability to listen and speaking. The Cultural Festival of the School of Foreign Languages begins in the third week of the fall semester of each year and continues into the spring semester of the second year, throughout the school year. For students who are interested in translation in the lower grades, there are main practical activities available like the English Corner in the third week of the first semester, the Vocabulary and English Drama Competition in the eleventh week, and the Foreign Classic Reading Competition in the twelfth week. For the senior students, We pay attention to the training of translation skills and rely on the practice internship platform to update the practical teaching content. The main practical activities are expressive translation and museum volunteers (practical activities usually begin from August to Mid-September). Interpretation and translation contests usually held in the eighth week of each semester. In this way, our practical activities will continue from the first semester to the seventh semester, and we will achieve continual progress and the success of truly combining the professional theory and practice of the translation direction and the organic integration of professional theory and practical teaching.

Second, from the point of view of practical teaching system, the reform and breakthrough of it rely on the traditional framework of practical teaching. We should activate the second classroom activities, and combine the practical teaching in translation direction with the innovative practice implemented by school and the tutor's studio. Above all, the focus is on the cultivation of students' innovative abilities. As illustrated in the figure below: set up a practical teaching team in the direction of English translation and make full use of teachers' adequate guidance. Moreover, set up translation and interpretation workshops. Based on the curriculum arrangement in each semester for different grades, from lower to higher, they participate in diverse practical activities and actively declare innovative entrepreneurship projects accordingly. In practical activities, students will enhance professional basic knowledge, accumulate experience, and achieve a great balance between book learning and practical learning.

Third, we should build a team of practical teaching in the direction of English translation and 
standardize practical teaching documents. We should optimize the structure of the practical teaching team and advocate teachers with high academic qualifications and high professional titles to enter practical teaching. There are ten full-time teachers of the English translation, and they can be divided into two groups: translation and interpretation. Under the group leader system, each group has four teachers including two foreign teachers and about 28 to 35 students. Teachers should give full play to their own guiding role, build more platforms and provide materials for students. Under the leadership of teachers, students can complete professionally theoretical activities, professional practice activities, and innovative projects. In order to ensure that each job is carried out successfully, we should quantify the work and allocate funds in each school year.

Fourth, update and apply practical teaching equipment and resources appropriately to improve the quality of practical teaching and the ability of students' operation. At present, the School of Foreign Languages boasts one interpreting laboratory and nine classrooms of pronunciation multimedia, which have fully met the requirements of equipment and resources of practical teaching for English translation majors. Therefore, we need to improve the structure and hierarchy of practical teaching content in practical training and internships to expand the selecting space for students' independent learning which can satisfy the needs of students' individualized grow. Strengthen the improvement of the comprehensive laboratory of interpretation and translation in our colleges to make better use of laboratory resources, and realize the open management of laboratories to build a platform for students to learn independently.

Fifth, actively expand the practical teaching internship base of translation major and implement the construction of internship bases inside and outside the school. We can set the current plan of in our school which aims at applying national and provincial off-campus practice education bases as a beginning to focus on the "excellent program" and other teaching reform projects to further promote the establishment of off-campus practical teaching base and the innovation of school-enterprise cooperation model. Translation major in the School of Foreign Languages will build more than 3 or 4 long-term stable practical teaching bases according to their professional characteristics. Such as the Government office of Foreign Affairs, Jingzhou Merchants, museums and related enterprises and companies engaged in translation. Based on the framework of the existing practical teaching system of the 2016 talent cultivation program, the School of Foreign Language began to put more emphasis on the management of graduation internships which implemented under the strict guidance of professional instructors with concrete plan and purpose from the school year of 2017 to 2018 .

\section{IV.Conclusion}

In the process of talent cultivation in contemporary universities, practical teaching operates a major part that it is the main method and means to cultivate students' practical ability and creativity and the process of putting theoretical knowledge into practice. According to the investigation and research study on the recent condition of the practical teaching system for English translation majors, we realize the importance of practical teaching. According to the assumption of practicing teaching reform, the practical teaching content of the English translation major will be implemented well combined with social requirements for English translation majors. 


\section{References:}

[1]. The English group of College Foreign Language Teaching Committee. English teaching Syllabus for English majors [M]. Shanghai: Shanghai Foreign Language Education Press, 2000.

[2]. The Professional Cultivation Program for Yangtze University Undergraduates in 2016. Yangtze University Academic Affairs Office 